\title{
The use of intravenous meptazinol for analgesia in colonoscopy
}

\author{
P.R.H. Barnes, C.B. Williams, R.L. Davies, C.S.B. Childs, A. Hedges and \\ D. Graham
}

St Mark's Hospital, City Road, London, UK.

\begin{abstract}
Summary: A double blind study comparing intravenous pethidine and meptazinol has been performed to establish the efficacy and safety of meptazinol as an analgesic agent in colonoscopy. Twenty two patients received pethidine and 23 patients received meptazinol and no difference in analgesic effect or sedative effect could be demonstrated either by observer or patient assessment using a visual analogue scale. A group of 10 patients in the pethidine group and 9 in the meptazinol group had continuous recording of electrocardiogram, pulse rate and blood pressure throughout the procedure. Significant falls in both systolic and diastolic blood pressure were recorded in the pethidine group but not the meptaxinol group. Benign cardiac arrhythmias were recorded in both groups before and after the administration of premedicant drug and 1 patient in each group had transient ST depression. Side effects were recorded with equal frequency in each group except for vomiting which occurred in 5 of 23 meptazinol patients but none of the pethidine patients.

Meptazinol is an effective analgesic drug in colonoscopy which produces less cardiovascular depression than pethidine and thus may be useful in selected patients especially the elderly or those with known cardiovascular disease.
\end{abstract}

\section{Introduction}

Fibre-optic colonoscopy may be an uncomfortable procedure and intravenous analgesia is commonly used usually combined with a sedative drug immediately prior to the procedure. Pethidine $50-100 \mathrm{mg}$ is the analgesic most often chosen while diazepam $5-10 \mathrm{mg}$ is usually chosen as the sedative drug because of its amnesic properties. Both drugs, when used intravenously, may depress the cardiovascular and respiratory systems and their simultaneous administration may compound this problem (Gilman et al., 1975).

Meptazinol is a new potent analgesic compound (Hedges \& Turner, 1983) that has no significant effect on the cardiovascular or respiratory system in therapeutic doses (Gareth Jones, 1983; Budd, 1976). It has a short duration of action (Robson, 1983) and mild sedative properties and these features suggested to us that it might have advantages over conventional

P.R.H. Barnes, M.B., B.S., F.R.A.C.P.; C.B. Williams, B.M., F.R.C.P.; R.L. Davies, B.Sc., S.R.N., R.M.N.; C.S.B. Childs, M.B., B.S., F.F.A.R.C.S.; A. Hedges, Ph.D.; D. Graham. M.B., B.S., F.R.C.S.

Correspondence: P. Barnes, St Mark's Hospital, City Road, London ECIV 2PS, UK.

Accepted: 13 September 1984 analgesia for out-patient colonoscopy. The efficacy and cardiovascular effect of meptazinol have been compared to pethidine in a double blind study.

\section{Methods}

Patients were recruited from those attending St Mark's Hospital for routine outpatient colonoscopy. Forty five consecutive patients who gave informed consent were included and the study was approved by the Hospital Ethical Committeee.

Before pre-medication, patients were asked to rate their level of discomfort on a visual analogue scale of $0-100 \mathrm{~mm}$, (0 corresponding to nil and 100 very severe). Similar recordings were made of sedation (0 corresponding to fully awake and 100 to almost asleep) on an analogue scale. In 9 meptazinol and 10 pethidine patients, recordings of blood pressure and pulse rate were made before colonoscopy and at $3 \mathrm{~min}$ intervals during the procedure using a Dinamap 845 recorder and printer. A continuous electrocardiogram was monitored by an observer before premedication and throughout the colonoscopy; arrhythmias and ST segment changes were noted. A nurse/observer standing beside the patient rated the patient's level of 
Table I Observer and patient assessment of sedation on a $100 \mathrm{~mm}$ visual analogue scale.

\begin{tabular}{|c|c|c|c|c|c|c|}
\hline & & \multicolumn{2}{|c|}{ Observer assessment } & & \multicolumn{2}{|c|}{ Patient assessment } \\
\hline & & $\begin{array}{c}\text { median } \\
\text { score }\end{array}$ & $\begin{array}{c}\text { interquartile } \\
\text { distance }\end{array}$ & & $\begin{array}{c}\text { median } \\
\text { score }\end{array}$ & $\begin{array}{c}\text { interquartile } \\
\text { distance }\end{array}$ \\
\hline \multirow[t]{2}{*}{$\begin{array}{l}\text { Meptazinol } \\
\text { patients }\end{array}$} & $\begin{array}{l}\text { during } \\
\text { colonoscopy }\end{array}$ & 4 & 26 & $\begin{array}{c}\text { pre } \\
\text { colonoscopy }\end{array}$ & 6 & 27 \\
\hline & $\begin{array}{l}\text { after } \\
\text { colonoscopy }\end{array}$ & 2 & 13 & $\begin{array}{c}\text { post } \\
\text { colonoscopy }\end{array}$ & 23.5 & 40.5 \\
\hline \multirow[t]{2}{*}{$\begin{array}{l}\text { Pethidine } \\
\text { patients }\end{array}$} & $\begin{array}{l}\text { during } \\
\text { colonoscopy }\end{array}$ & 18 & 47.75 & $\begin{array}{c}\text { pre } \\
\text { colonoscopy }\end{array}$ & 11.5 & 31 \\
\hline & $\begin{array}{l}\text { after } \\
\text { colonoscopy }\end{array}$ & 8 & 22.75 & $\begin{array}{l}\text { post } \\
\text { colonoscopy }\end{array}$ & 28.5 & 52.75 \\
\hline
\end{tabular}

$0=$ completely awake; $100=$ almost asleep.

discomfort and sedation on a visual analogue scale during the procedure and at completion. The colonoscopist rated the degree of difficulty of each colonoscopy and patients were asked 45 minutes after completion to rate their level of sedation and discomfort during the procedure.

Patients were randomised under double blind conditions to receive pethidine $50 \mathrm{mg}(1 \mathrm{ml})$ or meptazinol $50 \mathrm{mg}(1 \mathrm{ml})$ as a slow intravenous injection. The protocol allowed a further $25 \mathrm{mg}$ of analgesic drug to be given during the procedure if pain was severe, followed by an injection of pethidine if pain remained unrelieved. Other sedative and antispasmodic drugs were not used.

\section{Results}

Twenty two patients received pethidine and 23 patients received meptazinol. Groups were similarly matched for age, sex and weight and the degree of difficulty, as rated by the colonoscopist, was similar in each group. The Kruskal Wallis test was used to compare differences between drugs and the Wilcoxon'Rank test was used to compare time differences in the same group. Numbers requiring an extra dose of analgesic agent were similar (5 meptazinol, 6 peth-i idine) in both treatment groups. One meptazinol $N$ patient received an injection of $50 \mathrm{mg}$ pethidine. Noo pethidine patient required more than $75 \mathrm{mg}$.

\section{Sedation (Table I)}

Higher sedation scores were rated by the observer $\vec{n} \overrightarrow{0}$ the pethidine group during the procedure compared $400 \%$ the meptazinol group, this however did not reash' statistical significance. There were no significant difi-O ferences between pethidine and meptazinol in patients' assessment of sedation.

\section{Discomfort (Table II)}

On a visual analogue scale, meptazinol was as effective as pethidine in relieving the discomfort of colonoscopy, in both patient and observer assessment.

Table II Observer and patient assessment of discomfort during colonoscopy on a $100 \mathrm{~mm}$ visual analogue scale.

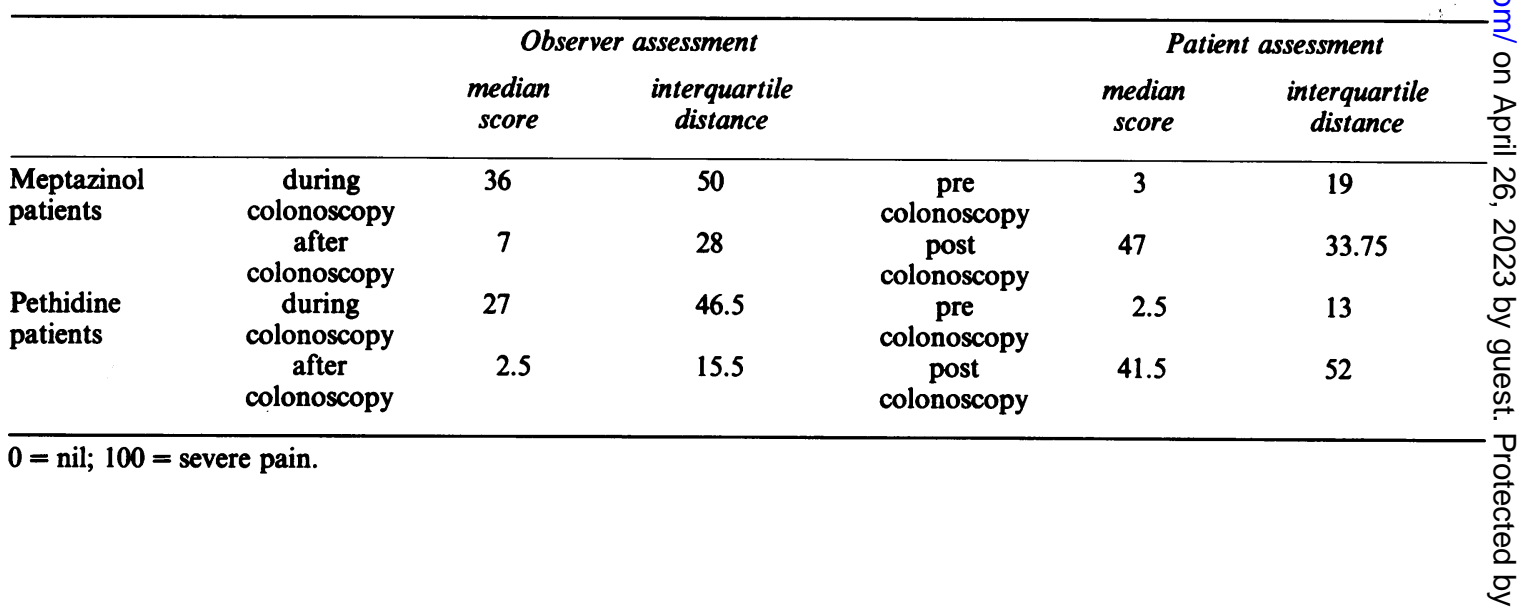




\section{Haemodynamic effects (Figure 1)}

Systolic blood pressure fell in both groups tested from high pre-colonoscopy levels. A significantly greater fall in systolic blood pressure was observed in the pethidine group $(P<0.05$ at $9 \mathrm{~min})$. One patient in the pethidine group had a fall in systolic blood pressure to $60 \mathrm{~mm} \mathrm{Hg}$ while a further 3 had falls to less than $80 \mathrm{~mm} \mathrm{Hg}$. In no patient receiving meptazinol did systolic blood pressure fall below $100 \mathrm{~mm} \mathrm{Hg}$.

A significantly greater fall in diastolic blood pressure was observed in the pethidine group $(P<0.05$ at
$12 \mathrm{~min}$ ). The diastolic blood pressure in the pethidine group fell in one patient to $30 \mathrm{~mm} \mathrm{Hg}$ and in 4 others to less than $45 \mathrm{~mm} \mathrm{Hg}$. In no patient receiving meptazinol did diastolic blood pressure fall below $50 \mathrm{~mm} \mathrm{Hg}$.

Pulse rate in the pethidine group rose above the baseline mean of 90 beats/min while those in the meptazinol group fell sightly. There was a significant difference in pulse rate between groups at 6 minutes $(P<0.02)$. Pulse rate did not rise above 110 beats $/ \mathrm{min}$ in either patient group.

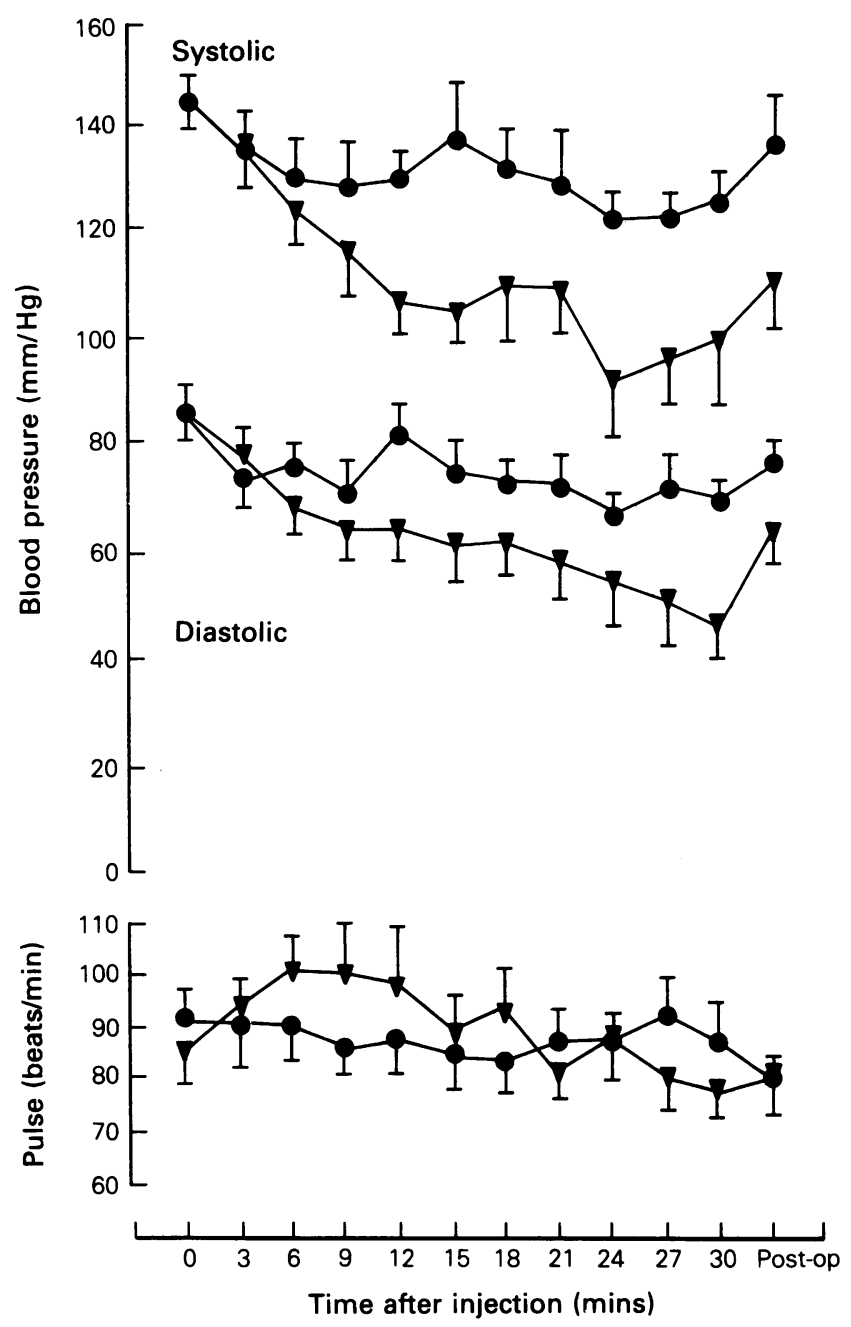

Figure 1 Variation of mean systolic and diastolic blood pressures $(+$ s.e.mean) and mean pulse rate $(+$ s.e.mean) in meptazinol and pethidine groups during colonoscopy. (O) Meptazinol group $(n=9)$. ( $\boldsymbol{\nabla})$ Pethidine group $(\mathrm{n}=10)$. 


\section{Electrocardiographic abnormalities}

Ventricular, nodal and atrial ectopics were seen in both groups of patients before premedication as well as sporadically throughout the procedure. One patient in the meptazinol group with known cardiovascular disease was noted to have ST depression before administration of analgesic agent this persisted for some time during the procedure but had returned to normal at completion of colonoscopy. One patient in the pethidine group without known ischaemic heart disease was noted to have ST depression at $15 \mathrm{~min}$, associated with a fall in systolic BP to $62 \mathrm{~mm} \mathrm{Hg}$.

\section{Side effects}

Side effects were common in both groups and may have been a consequence of vagal stimulation of the colonoscopic examination. Sweating, pallor and dizziness were seen with equal frequency in each group and were usually mild and transient. Five patients in the meptazinol group had vomiting during or after the procedure which in 3 cases persisted intermittently for 2-3 hours.

\section{Discussion}

During colonoscopy pain tends to be brief in duration but intense in severity. In choosing an appropriate analgesic the colonoscopist must weigh the benefits for the patient against the risk of significant drug side effects.

Pethidine has been widely used in endoscopy departments for some years and hypotensive episodes are reported, especially in elderly patients. The one death in the reported series of colonoscopic complications from our unit was thought to be due to the effect of premedication in an elderly patient (McCrae et al.,

\section{References}

BUDD, K. (1976). Meptazinol - A new analgesic. Effects on haemodynamic stability. Acta Anaesthesiologica Belgica, 27, 137 .

COTTON, P.B. \& WILlIAMS, C.B. (1980). Practical Gastrointestinal Endoscopy. 1st Ed, p. 92, Blackwell: Oxford.

FLETCHER, G.F., EARNEST, D.L., SHUFORD, W.F. \& WENGER, N.K. (1968). Electrocardiac changes during routine sigmoidoscopy. Archives of Internal Medicine, 122, 483.

GARETH JONES, J. (1983). The respiratory effects of meptazinol. Postgraduate Medical Journal, 59, (suppl. 1), 72.

GILMAN, AG., GOODMAN, L.S. \& GILMAN, A. (1975). The Pharmacological Basis of Therapeutics. 6th Ed, p.467, Macmillan: New York.
1983). The adverse cardiorespiratory effects of in- $\frac{0}{2}$ travenous pethidine and other opiates are well recogn- $\varrho$ ised and it is thus desirable to consider the use of $z$ alternative analgesic agents in the older age group and $\stackrel{\varnothing}{\complement}$ those with known cardiorespiratory disease. Our $\subsetneq$ study confirms that profound hypotension occurs in a $\overrightarrow{\vec{F}}$ significant proportion of patients receiving pethidine $-\frac{\vec{O}}{0}$ for colonoscopy, whereas no significant hypotension $\frac{\bar{O}}{0}$ was recorded in the meptazinol group (systolic BP in $\overline{\bar{c}}$.

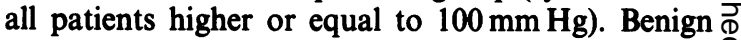
atrial and ventricular ectopics were common in both $\frac{\Omega}{\Omega}$ treatment groups during colonoscopy in accordance $s$ with previous studies in patients undergoing sig- $\overrightarrow{0}$ moidoscopy (Fletcher et al., 1968).

There was a trend suggesting lower sedation scores $\vec{\rho}$ in the meptazinol group but this did not reach $\overline{0}$ statistical significance.

Meptazinol appeared to both patient and observer $\frac{3}{\sigma}$ to be as effective an analgesic agent as pethidine. Despite analgesia, most patients experience some pain $\vec{\omega}$ during colonoscopy and indeed painful responses are $a$ 'useful warning to the colonoscopist' (Cotton and ${ }_{-}^{N}$ Williams, 1980) of excessive stretch or pressure.

Vomiting occurred in 5 of the 23 meptazinol patients and we were unable to identify those at risk of 3 this reaction by using a small test dose.

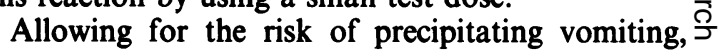
intravenous meptazinol may be a useful agent for use $\overrightarrow{0}$ in patients undergoing colonoscopy, in particu通 of elderly patients or those with known cardiorespiratoji disease.

\section{Acknowledgements}

This study was performed with the aid of a grant from Wyeth Laboratories Ltd, who also supplied the coded drugs. We are $\frac{}{3}$ also grateful to Miss Catherine Charlery who typed the $\frac{F}{0}$ manuscript.

HEDGES, A. \& TURNER, P., (1983). The use of intramuscular meptazinol in the relief of postoperative pain after abdominal hysterectomy - a review. Postgraduate Medical 윽 Journal, 59, (suppl. 1), 32.

MCCRAE, F.A., TAN, K.G. \& WILlIAMS, C.D. (1983). 을 Towards safer colonoscopy: a report on the complications $\mathrm{N}$ of 5000 diagnostic and therapeutic colonoscopies. Gut, 24, $\odot$ 376.

ROBSON, P.J. (1983). A clinical review of parenteral mep- N tazinol. Postgraduate Medical Journal, 59, (suppl. 1), 85.

\section{(1)

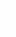

